\title{
A crença nas palavras: (des)construções lexicais em antropônimos de líderes religiosos
}

DOI: http://dx.doi.org/10.21165/el.v48i2.2446

\section{Carlos Alexandre Gonçalves ${ }^{1}$}

\section{Resumo}

Neste artigo, tomamos por base formações expressivas oriundas de prenomes ou sobrenomes de personagens polêmicos na esfera religiosa, a exemplo de "Pedir Mais Cedo" e "Silas Mala Cheia", desconstruções lexicais advindas de antropônimos de dois conhecidos pastores neopentecostais: Edir Macedo e Silas Malafaia. Nossa principal meta é mapear os processos morfossemânticos envolvidos nessas cunhagens e observar a gama de estratégias de que se vale o falante na expressão de pontos de vista através de (re)análises morfológicas.

Palavras-chave: morfologia; cruzamento vocabular; analogia; criatividade.

1Universidade Federal do Rio de Janeiro, Rio de Janeiro, Brasil;

carlexandre@bol.com.br; https://orcid.org/0000-0003-3672-3852 
The faith in words: lexical (de)constructions in names of religious leaders

\begin{abstract}
In this paper, we analyze new expressive formations of names of controversial leaders in the religious sphere, such as "PedirMaisCedo" ("ask for it sooner") and "Silas Mala Cheia" (Silas "crowded suitcase"), lexical deconstructions from two well-known Brazilian ministers: Edir Macedo and Silas Malafaia.Our main goal is to map the morpho-semantic processes involved in these coinages and to observe the range of strategies that the speaker uses to express points of view through morphological (re)analysis.
\end{abstract}

Keywords: morphology; lexical blend; analogy; creativity.

\title{
1. Palavras iniciais
}

Neste trabalho, utilizamos um conjunto de (des)construções lexicais que, em comum, partem de nomes de personalidades polêmicas na esfera religiosa, como o Bispo Marcelo Crivella, atual prefeito da cidade do Rio de Janeiro. O principal objetivo do artigo é verificar que processos morfofonológicos são utilizados e com que funções essas formações são cunhadas. Para tanto, o texto se estrutura da seguinte maneira: primeiro, apresentamos as principais motivações da criação lexical e, logo após, o corpus utilizado na análise. Por fim, discutimos a variedade de estratégias morfossemânticas de cunho humorístico, jocoso e crítico de que o falante se vale para externar sua opinião a respeito dos líderes das principais igrejas evangélicas brasileiras. Também pretendemos destacar as fronteiras entre processos não concatenativos de formação de palavras, como o cruzamento vocabular ('crentino' << 'crente + 'cretino'), e mecanismos de natureza analógica, como decomposições estruturais ('deter gente' $<$ 'detergente') e substituições sublexicais ('boadrinha' <<'madrinha').

\section{Motivações da criação lexical}

Quando o falante cria ou emprega uma palavra morfologicamente complexa, há, subjacente ao ato, motivação de diversas ordens. Basílio (1987) sustenta que a utilização e a criação de construções morfológicas estão relacionadas aos seguintes fatores:

(i) necessidade de nomeação;

(ii) adequação ao contexto sintático;

(iii) intenções do usuário da língua. 
A necessidade de cunhar novas experiências no mundo corresponde à função de denominação ou rotulação (relacionada com o aspecto semântico). Por sua vez, a adequação ao contexto sintático diz respeito à função de mudança categorial, que ocorre por questões mais tipicamente gramaticais. Por fim, propósitos, desejos e crenças do falante equivalem à função expressiva de avaliação ou discursiva.

Falamos em função de rotulação quando novas palavras aparecem para nomear invenções e fenômenos até então desconhecidos, conceitos diferentes ou, ainda, para cunhar tendências do mundo contemporâneo. Assim, temos a necessidade de nomeálos para nos referirmos a eles, a exemplo da recente sufixação "blogueiro", criada para rotular quem faz ou aprecia blogs. A função de mudança categorial está relacionada à necessidade de se empregar palavra de determinada classe em ambiente sintático que requer classe diferente. Por exemplo, a forma "sextar", recém-cunhada por jovens, vale-se do acréscimo da terminação verbal -ar à forma inglesa "sexta", de "sexta-feira", levando, assim, a uma mudança categorial, ou seja, a partir de um nome formou-se um verbo que designa algo como "finalmente chegou a sexta-feira" ("sextou"; "amanhã vai sextar" etc.).

A função discursiva caracteriza-se pela necessidade de o falante expressar carga emocional variada a partir do uso de processos morfofonológicos diversos, ou seja, de acrescentar conteúdos subjetivos a uma forma lexical neutra, como em "juizeco". Exemplo típico de morfologia avaliativa é a gradação afixal, com a qual se expressa a atitude do falante (daí o nome alternativo de função atitudinal).

Como observa Gonçalves (2016), afixos de grau podem envolver a manifestação de carinho, ternura, amor, simpatia/empatia, não somente para com pessoas, como é o caso da modificação de antropônimos ("Carlitcho", "Carmita", "Soninha") e hipocorísticos ("Leca", para "Lê" de "Alessandra"; "Betinha", para "Bete" de "Elisabete"), mas também em relação a outros seres animados ("leãozito", para "leão"). De acordo com Gonçalves (2016, p. 42), o diminutivo "pode ser a expressão de compaixão (tadinho) ou atenuar condições miseráveis, deficiências e males (aleijadinho)". Por outro lado, "pode envolver a manifestação de desprezo (livreco, velhote)", ou, ainda, "a designação de coisas de pouco valor ou de pouca importância (namorico) ou formas de tratamento depreciativo (gentalha, povinho)". Esses exemplos demonstram as possibilidades de carga emocional variada nos afixos de grau, que podem ser usados com características afetivas, mas também podem ser pejorativos, como se vê nos exemplos a seguir, extraídos de Gonçalves et al. (2010, p. 151):

(01) Abelardo é resmungão, reclamão e, ainda por cima, bocão...

O Rogerinho é pidão demais... Mó filão... Vive me pedindo cigarro!

Não gosto desse tipo muito entrão. 
Em todos os exemplos de (01), há função de alteração categorial, pois se parte de um verbo para formar um substantivo. Associada a essa função está a expressão do ponto de vista do falante, que considera excessiva, pelo praticante, a ação especificada na base. O teor negativo é da construção como um todo, pois a base nem sempre é depreciativa (p. ex., não há nada de mal em "entrar" e "pedir"; a negatividade vem da habitualidade dessas práticas). Dados como "babão", "olhão" e "reclamão" estão relacionados à estereotipia, ou seja,

[...] ao caráter social da deturpação, uma vez que o exagero é avaliado negativamente pelo falante, que manifesta um posicionamento crítico em relação à entidade referida. Tais usos estão diretamente ligados à intensidade, atualizada na construção pelo aspecto iterativo, que imprime às formas $X_{V}$-ão caráter nitidamente depreciativo. (SOUZA; GONÇALVES, 2018, p. 157).

Exemplo recente de construção morfológica avaliativa é X-iane, encontrada predominantemente em ambiente virtual. A partir dos dados relacionados em (02), todos extraídos de Andrade e Rondinini (2016), constata-se que a partícula -iane se agrega prioritariamente a bases adjetivas para formar um adjetivo avaliativo, ao atribuir propriedade ou qualidade à entidade referida, denotando, sobretudo, desprezo ou qualquer outra avaliação negativa.

$\begin{array}{llll}\text { escrotine } & \text { falsiane } & \text { sonsiane } & \text { gordiane } \\ \text { baleiane } & \text { cretiniane } & \text { putiane } & \text { cadeliane }\end{array}$

Em resumo, a função expressiva de avaliação revela tudo o que passa pelo julgamento do falante-emissor, daí Gonçalves (2016) utilizar o termo atitudinal para denominar essa faceta das construções morfológicas complexas. Praticamente todos os exemplos de nosso corpus envolvem avaliação negativa (crítica, ironia, deboche, desapreço) de líderes religiosos. Os dados que embasam a análise foram retirados de fontes informais,a exemplo do site Desciclopédia ${ }^{2}$, e de redes sociais, como o Twitter, o Facebook, o Instagram e o WhatsApp. Muitos foram rastreados com o auxílio da ferramenta eletrônica Google 3 . Com essa ferramenta, chegamos a vários blogs criados com a intenção de demonstrar desapreço pelos seguintes líderes religiosos, alguns também políticos: (a) Silas Malafaia (Líder e fundador da Assembleia de Deus Vitória em Cristo), (b) Edir Macedo (Fundador da Igreja Universal do Reino de Deus - IURD),

2 Escrita com a colaboração de seus leitores, a Desciclopédia é "um site de humor debochado e seu conteúdo não deve ser levado a sério. Todas as nossas regras e políticas convergem para um só princípio: ser engraçado e não apenas idiota" (http://bit.ly/2RV4nNq). Acesso em: 15 abr. 2018.

3 Agradeço à aluna Gizelli da Silva C. Maturgo por disponibilizar um pequeno conjunto de formações envolvendo as personalidades aqui em foco. 
(c)Valdemiro Santiago (Líder da Igreja Mundial do Poder de Deus), (d) Marco Feliciano (Líder da Catedral do Avivamento e também deputado federal), (e) Cabo Daciolo (candidato à presidência da república em 2018) e (f) Marcelo Crivella (Bispo da IURD e atual prefeito do Rio de Janeiro).

\section{3. (Des)construções lexicais envolvendo nomes de líderes religiosos}

Na manipulação formal envolvendo nomes de líderes religiosos, pudemos observar, nos valendo das palavras de Sandman (1989, p. 59), "uma especificidade semântica carregada, em sua maioria, de emocionalidade depreciativa e com pitadas de ironia". Desse modo, criações jocosas nascem do sentimento de repulsa e reprovação a esses líderes, muitas vezes envolvendo crítica explícita em relação à sua conduta cristã e/ou moral. Associadas ao humor, tais inovações culminam em construções carregadas de tom exclusivamente depreciativo, funcionando como impressões negativas sobre esses religiosos, todos evangélicos de orientação neopentencostal ${ }^{4}$. Comecemos com o conjunto de referências ao Pastor Silas Malafaia, psicólogo e pastor-presidente da Assembleia de Deus Vitória em Cristo $(A D V C)^{5}$.

De acordo com o Wikipédia, Malafaia é bastante conhecido por sua atuação política e pelo discurso agressivo sobre temas como direitos dos homossexuais e aborto, bem como por defender a chamada teologia da prosperidade ${ }^{6}$. Talvez em função dessa defesa, muitas reanálises envolvendo parte de seu sobrenome exploram a relação metonímica entre dinheiro e mala, uma vez que, recentemente, muitos eventos envolvendo dinheiro ilícito foram associados a malas. Nas reanálises a seguir, mala- é interpretada como substantivo, fazendo com que a sequência não morfêmica faia seja substituída por um adjetivo e o todo interpretado como um SN do tipo S+Adj. Para facilitar a formatação dos exemplos em bloco, fornecemos apenas os endereços, considerando que a data de acesso foi sempre a mesma: 15/04/2019.

40 neopentecostalismo - ou terceira onda do pentecostalismo - é um movimento sectário dissidente do evangelismo que congrega denominações oriundas das igrejas cristãs tradicionais (batistas, metodistas, adventistas etc.).

5 Em sua página oficial, a Assembleia de Deus Vitória em Cristo é descrita como um ministério da Assembleia de Deus, fundada em 1959, no Rio de Janeiro. Possui atualmente mais de 100 congregações em todo o Brasil e é uma das organizadoras da Marcha para Jesus e do programa televisivo Vitória em Cristo. https://www.advec.org/. Acesso em: 15 abr. 2018.

6 Também conhecida como Evangelho da prosperidade, a chamada teoria da prosperidade "é uma doutrina religiosa cristã que defende que a bênção financeira é o desejo de Deus para os cristãos e que a fé, o discurso positivo e as doações para os ministérios cristãos irão sempre aumentar a riqueza material do fiel" (https://pt.wikipedia.org/wiki/Teologia_da_prosperidade). Acesso em: 15 abr. 2018. 
Apesar de termos, em (03), casos clássicos de analogia, mantém-se a estrutura métricoprosódica da palavra-base: um quadrissílabo paroxítono. No entanto, por envolver a estruturação interna de palavras, pode ser chamada de decomposição sublexical (GONÇALVES, 2016), na qual, por questões expressivas e com base na forma, reconhecese uma unidade lexical em itens não necessariamente complexos. Henriques (2007) se refere a esse expediente usando a expressão "falso cruzamento vocabular", uma vez que há uma reestruturação interna na forma de base, de tal modo que o produto se assemelha a um cruzamento. Na imagem abaixo, além da decomposição sublexical, explora-se um recurso gráfico (o \$) para assegurar o conteúdo da "mala":

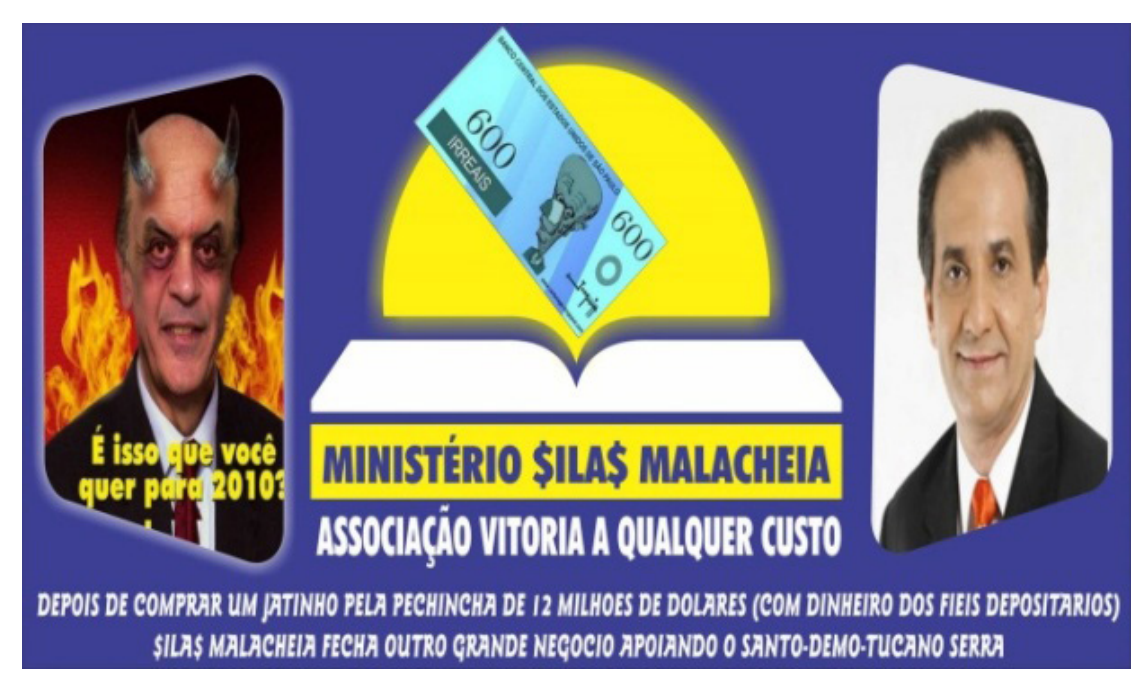

Figura 1. Silas Malacheia

Fonte: http://juinavermelha.blogspot.com/2010/09/nao-voto-mais-em-marina-e-digopor-que.html. Acesso em: 02 maio 2019.

Levando em conta a polissemia da palavra, "mala" também é usada em referência a alguém chato, inconveniente, sem graça. A expressão "mala sem alça" pode justificar essa extensão semântica, pois uma mala que não possui alça é, sem dúvida, algo difícil de carregar, inconveniente, e, por tabela, acaba designando, de acordo com o Dicionário Informal, "indivíduo chato, desagradável, aporrinhativo, desinteressante, cuja presença incomoda aos outros, pela obviedade e previsibilidade de seus conceitos e opiniões, nada 
tendo de relevante a acrescentar"7. O referido Pastor é visto pelos seus desafetos como alguém que reúne esses atributos e, por isso mesmo, são comuns reanálises como as feitas em (04):

(04) Silas Malafalsa (https://twitter.com/DCM_online/status/1053812269614817283) Silas Malaalfafa (https://piaui.folha.uol.com.br/materia/vitoria-em-cristo) Silas Mala Vaia (https://www.facebook.com/...Silas-Malavaia/140916732600581) Silas Malafanha (http://wp.clicrbs.com.br/espiadinha/2010/03/17)

Outra reinterpretação do sobrenome do Pastor se utiliza do hífen para separar a sequência mal-, relacionada ao oposto de "bem", pondo em xeque, com isso, a bondade que seria própria de cristãos, sobretudo líderes evangélicos:

$$
\begin{aligned}
& \text { Mal-afaia (https://www.youtube.com/watch?v=VNSYw8I36ic) } \\
& \text { Mal-afana (https://www.recantodasletras.com.br/humor/4379028) } \\
& \text { Mal-alface (Silas Malafaia e o seu vegetarianismo - Altnewspaper) } \\
& \text { Mal-afeto (https://www.pensador.com > Pensador > Autores > Helio Cruz) } \\
& \text { Mal-amado (cardosinho.blog.br/cidade/frase-20/) }
\end{aligned}
$$

Novamente aqui, preserva-se a estrutura métrica da palavra-matriz, de modo a não perder de vista a entidade referida. O hífen sinaliza a analogia e separa, no primeiro exemplo, o próprio sobrenome do religioso. Nos demais, a palavra invasora começa com /a/ e apresenta a fricativa labial, /f/, como estratégia de remeter à forma de base (exceção à última forma, que também apresenta uma labial, mas nasal, /m/).

Um exemplo que requer mais informaçõessócio-históricas é "Malarola" (http://bit.ly/3288BpE. Acesso em 15 abr. 2019), criação sem dúvida alguma motivada pela polêmica entre o pastor e o recém-falecido jornalista Ricardo Boechat, que, em seu programa na BandNews FM, afirmou que "no âmbito de igrejas neopentecostais estão acontecendo atos de incitação à intolerância religiosa". O bate-boca culminou com o jornalista mandando o pastor "procurar uma rola", além de acusá-lo de enriquecer às custas dos fiéis: "Você é um idiota, um paspalhão, pilantra, tomador de grana de fiel, explorador da fé alheia", disparou o jornalista, ao vivo. O comentário a seguir, extraído da mesma página de que extraímos os trechos entre aspas, faz uso da formação ora em análise ${ }^{8}$. A imagem, logo após, faz alusão explícita a esse episódio.

7 https://www.dicionarioinformal.com.br/mala+sem+al\%E7a/. Acesso em: 15 abr. 2019.

8 https://noticias.gospelmais.com.br/bate-boca-ricardo-boechat-malafaia-assista-77417.html. Acesso em 15 abr. 2019. 
(06) M. C. eu respeito o próximo, foi precisamente por isso que no comentário acima eu disse: "não sou a favor desse tipo de postura", se não fosse o malarola eu até poderia condenar mais o ato, mas é precisamente por ser esse preconceituoso que foi xingado é que eu não me importo, sinceramente ele pode ir se lascar (para não dizer coisas piores).

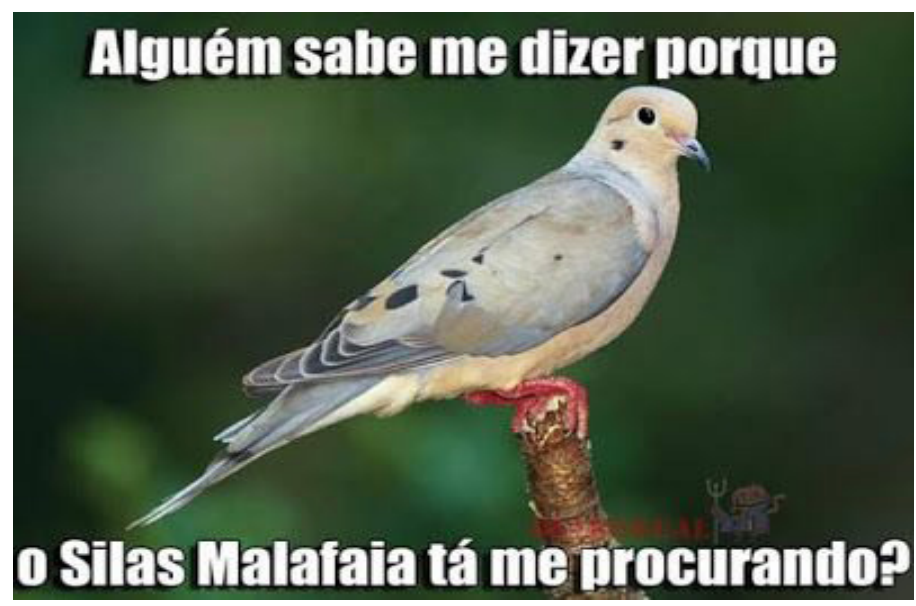

Figura 2. Silas Malarola

Fonte: http://bit.ly/2NBZn1P. Acesso em: 02 maio 2019.

Outro religioso de postura polêmica, tanto na esfera religiosa quanto no âmbito político, é Marco Feliciano, pastor da Catedral do Avivamento, igreja neopentecostal também ligada à Assembleia de Deus, e deputado federal agora eleito pelo PSC (Partido Social Cristão).

De acordo com o Wikipédia,

[...] por diversas vezes Feliciano tentou votar um projeto que anulava trechos de uma resolução do Conselho Federal de Psicologia, que proíbe os profissionais da área de psicologia de colaborarem com eventos e serviços que ofereçam tratamento para a homossexualidade e também veda manifestações que reforcem preconceitos sociais em relação aos homossexuais.[...] Conseguiu aprovar a proposta, apelidada pela imprensa do país, de "cura gay". (https://pt.wikipedia.org/wiki/Marco_Feliciano. Acesso em: 02 maio 2019).

Em nota pública, a ONG Anistia Internacional afirmou que as posições discriminatórias em relação à população LGBT, expressas em diferentes ocasiões pelo deputado Marco Feliciano, "o tornam uma escolha inaceitável para a presidência da Comissão de Direitos Humanos e Proteção de Minorias". Além disso, alerta ser "grave que tenha sido alçado ao posto a despeito de intensa mobilização da sociedade em repúdio a seu nome" (www.brasildefato.com.br/node/12457/. Acesso em: 15 abr. 2019). Talvez por conta de 
sua conduta em relação aos direitos LGBT,todas as inovações feitas com o sobrenome de Marco Feliciano exploram a reanálise da parte final do seu sobrenome, graças à semelhança entre a terminação ano e a palavra "ânus". Formações debochadas e irônicas criticam a postura do pastor-deputado, questionando, inclusive, sua heterossexualidade. A imagem a seguir usa a figura do pastor com a criação lexical "benegay", a partir de um remédio chamado "benegripe", numa clara alusão à "cura gay". Ressalte-se, ainda, a prefixação de in- ao sobrenome "Feliciano", sugerindo que o deputado não é feliz.

(07) Marco Feliz sem ânus (https://www.youtube.com/watch?v=tFO2yKWSos4)

Marco Feliz seu ânus (https://todebob.wordpress.com/2012/09/08/que-papelao-hein/)

Marco Feri seu ânus (https://brign.com > Fóruns > Salas de discussão > Mundo Aberto)

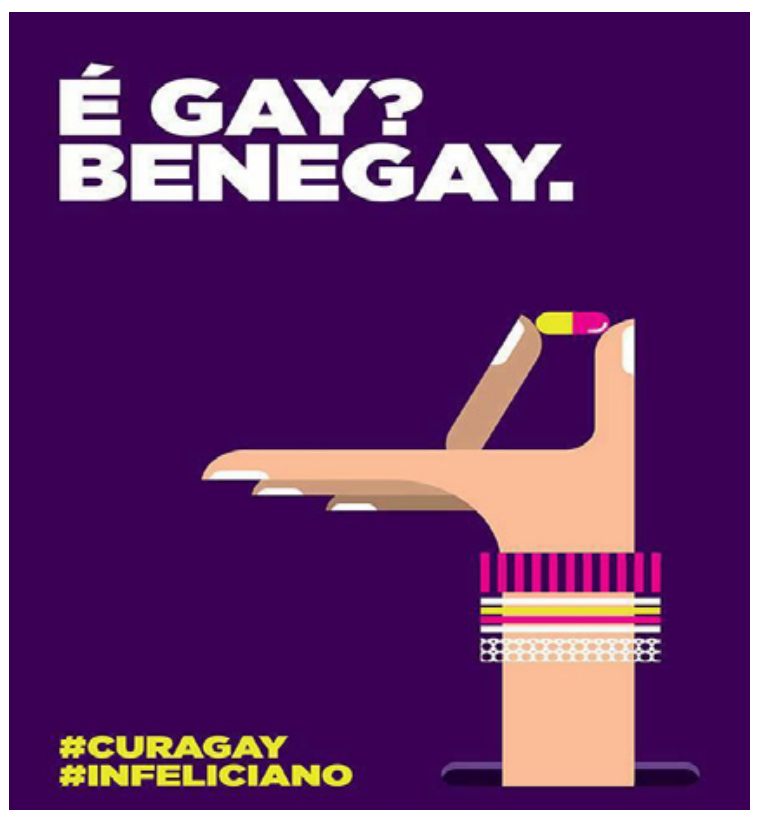

Figura 3. É gay? Benegay

Fonte: https://www.flickr.com/photos/79129506@N02/9087099990.

Acesso em: 02 maio 2019.

As formações em (07) também são casos clássicos de decomposição sublexical, pois a forma "Feliciano" apresenta complexidade morfológica que não é 100\% transparente para qualquer falante da língua, por conta da alomorfia na base Felic- e da falta de significado sincrônico para o sufixo (i)ano. Desse modo, a parte inicial do sobrenome é associada ao adjetivo "feliz", como esperado, mas também a "ferir", por rastreamento fonológico. A parte final é sempre decomposta da mesma maneira, sendo a sílaba /si/ vinculada à preposição "se" ou ao pronome "seu". A decomposição sublexical desfaz a palavra, transformando-a em grupos sintáticos variados. 
Brincadeira similar também ocorre com o prenome desse líder religioso. Nesse caso, somente recursos gráficos (caixa alta, itálico ou negrito) permitem evocar a forma livre correspondente, com reanálise tanto no prenome quanto no sobrenome, em (07). Numa página do Facebook, criada com o objetivo de reunir desafetos do pastor, usa-se um acento gráfico em desacordo com os padrões gráficos para marcar a associação:

(08) MarCU Feliciano (https://twitter.com/caiogervasoni. Acesso em: 02 maio 2019)

(09) Marcú Feliciânus (http://bit.ly/2Jgy3Sz. Acesso em: 02 maio 2019.)

Muitos casos de decomposição sublexical também aparecem com o sobrenome de outro reconhecido líder religioso, o Bispo Edir Macedo, criador da IURD (Igreja Universal do Reino de Deus) e proprietário do Grupo Record e da RecordTV, a terceira maior emissora de televisão do Brasil:
(10)
a. Pedir Maiscedo
b. Sumi Mais cedo
Iludir Maiscedo
Fugi Mais Cedo
Adir Mais cedo
Evadi Mais Cedo
Mentir Mais cedo
Fodi Mais Cedo
Transgredir Mais Cedo
Bebi Mais cedo

As construções em (10), além de desfazer o sobrenome Macedo em "mais cedo", fazem uso de um verbo de $3^{a}$ conjugação, majoritariamente (10a), ou de verbo de $2^{a}$. flexionado na $7^{\text {a }}$. pessoa do singular do pretérito perfeito (10b), o que garante a máxima semelhança fonética com o antropônimo "Edir", tendo em vista a supressão variável do rótico. As formas verbais em (10a) estão relacionadas ao domínio do lucro ou da subversão; as em (10b), por sua vez, referem-se a atitudes do falante pós-contato com o empresáriopastor: livrar-se logo da instituição que representa ("sumir", "fugir") ou trocar a religião por algo contrário ao que prega ("ingerir álcool", "praticar relação sexual"). Controverso pelo patrimônio que amealhou durante pouco tempo, a Desciclopédia, fonte da qual extraímos os dados em (10), assim se refere ao fundador e líder da IURD:

Um homem mercenário [...] que gosta de enganar os fiéis prometendo fazer cair fogo do céu só pra arrecadar o dinheiro do pão de cada dia. Um homem que tem um xaveco INIGUALÁVEL...

https://desciclopedia.org/wiki/Edir_Macedo. Acesso em: 15 abr. 2019 . 
A associação do sobrenome "Macedo" com a expressão "mais cedo" levou os integrantes do Pânico - programa humorístico inicialmente veiculado pela rádio Jovem Pan e posteriormente televisionado por duas emissoras, a Rede TV e a TV - a criar o personagem Didi Mais Cedo, hipocorizando o prenome do Bispo da IURD através da reduplicação da sílaba [dzi]:

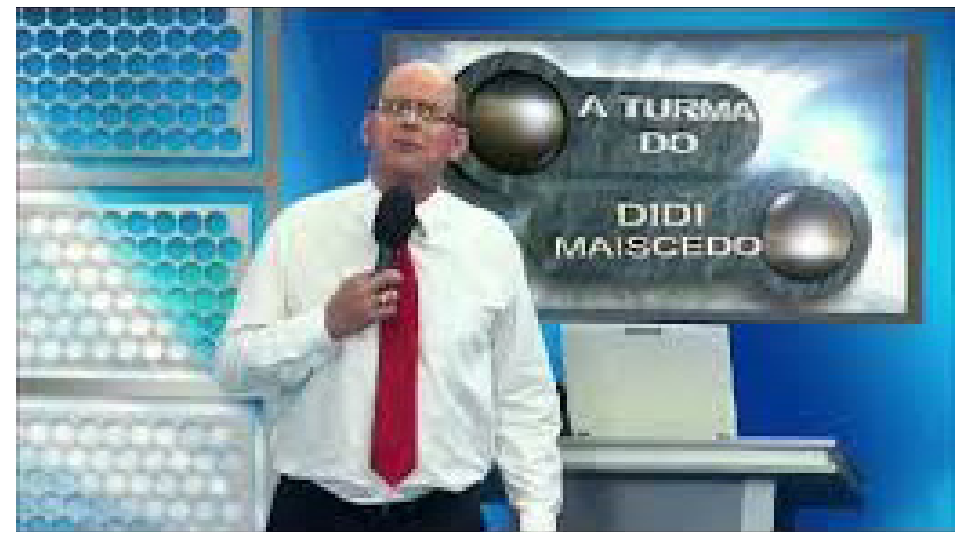

Figura 4. Didi Maiscedo

Fonte: https://www.youtube.com/watch?v=QJBg4BxC4uk. Acesso em: 15 maio 2019.

A decomposição do nome próprio "Macedo" pode explorar também a sequência /ma/, manipulada em várias substituições sublexicais (SSLS) com nomes comuns, nas quais essa sílaba, por equivaler ao adjetivo "má", é permutada pelo seu antônimo "boa" (os dados são de Andrade, 2009):
boacumba boadrasta
boaconha boadrinha

No caso do antropônimo em questão, a sequência fônica [ma] ora é mantida, ora substituída por [maw], sempre com a modificação do restante, ['sedu], pelo advérbio "cedo" ou por outro dissílabo paroxítono iniciado por /s/. Os dados não são exemplos de SSLs, pelo menos nos termos de Gonçalves, Andrade e Almeida (2012), uma vez que o resultado não constitui cruzamento vocabular, mas decomposições internas:

(12) Edir Má-seita (www.montfort.org.br/perguntas/ontem_hoje.html)

Edir Mal-cedo (ceifadores.com.br/novo/noticia/5550)

Edir Mau-cedo (www.krafta.cc/musica/cd-da-universal-do-reino-de-deus-2)

Edir Mau-sebo (https://poesiadashoras.wordpress.com/2015/09/30/sapateiro) 
Dados bastante interessantes são listados em (13) e podem ser denominados de substituição lexical, já que uma palavra inteira é utilizada na permuta com o sobrenome "Macedo". Como se vê, essas formas que aparecem na combinação com o prenome evocam o sobrenome ou pela sequência inicial ou pela sequência final, posições prosodicamente salientes, na visão de Beckmann (1998, p. 63). Segundo a autora, existe um pequeno inventário de posições linguisticamente privilegiadas "que desempenham papel importante nos sistemas fonológicos". Essas posições "apresentam uma vantagem perceptual no sistema de processamento, via proeminência psicolingüística ou fonética, em relação a posições não-privilegiadas". Dentre as várias destacadas por Beckmann, sílabas iniciais de raízes e a borda direita da palavra são posições perceptualmente mais marcadas, o que possibilita o rastreamento do sobrenome, por exemplo, pela rima com outras formas linguísticas, a exemplo dos primeiros casos de (13), a seguir:

(13) Edir Mancebo (https://www.youtube.com/watch?v=FWoV6X-jV-o)

Edir Placebo (https://plus.google.com/+CarlosTonyfer/posts/MgHQDZtJwUj)

Edir Bruxedo (http://bit.ly/2RV61yA)

Edir Azedo (https://twitter.com/_barreto81/status/1050031719963865088)

Edir Malandro (http://bit.ly/2XJ84LD)

Edir Maleta (zamze.net/610244.html)

Edir Macete (https://pt-br.facebook.com/edi.macete)

O último dado em (13) aparece em uma página do Facebook em que o criador mostra os diversos macetes dados pelo Bispo a pastores de sua igreja, ensinando-os como obter mais lucro de seus fiéis (https://www.facebook.com/edi.macete. Acesso em: 01 maio 2019). Na imagem a seguir, a referência ao Bispo como "Edi" parece intencional, uma vez que, na linguagem informal, essa palavra também faz alusão a "ânus" (cf. https://www.dicionarioinformal.com.br/edi/. Acesso em: 02 maio 2019).

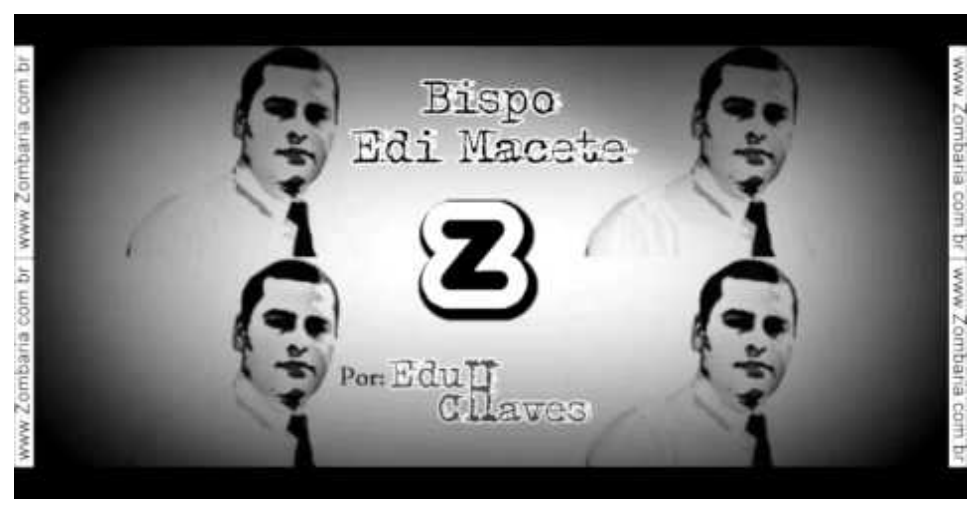

Figura 5. Edir Macete

Fonte: https://www.youtube.com/watch?v=z6kCkiDM_jc. Acesso em: 15 maio 2019. 
Outro religioso cujo nome aparece envolvido em (des)construções lexicais é Valdemiro Santiago, fundador e líder da Igreja Mundial do Poder de Deus (IMPD). A Wikipédia nos fornece a seguinte informação a respeito do autointitulado apóstolo:

\begin{abstract}
A Rede Record e a Folha Universal publicaram uma reportagem denunciando a compra de fazendas na região do Pantanal brasileiro, que Santiago teria feito com dinheiro dos fiéis da Mundial. Valdemiro é acusado de desviar os dízimos e as ofertas da instituição, através de filmagens em propriedades adquiridas por ele em nome da IMPD e documentos cartorários contendo sua assinatura e de sua cônjuge, a bispa Franciléia de Oliveira. Também foi acusado de usar irregularmente o passaporte diplomático com a sua esposa.
\end{abstract}

"Apóstolo Valdemijo Sandiabo" é o nome de um personagem satírico criado pelo já programa Pânico. No meme a seguir, reproduz-se a frase que se tornou marca de Valdemiro: "Eu to sendo perseguido".

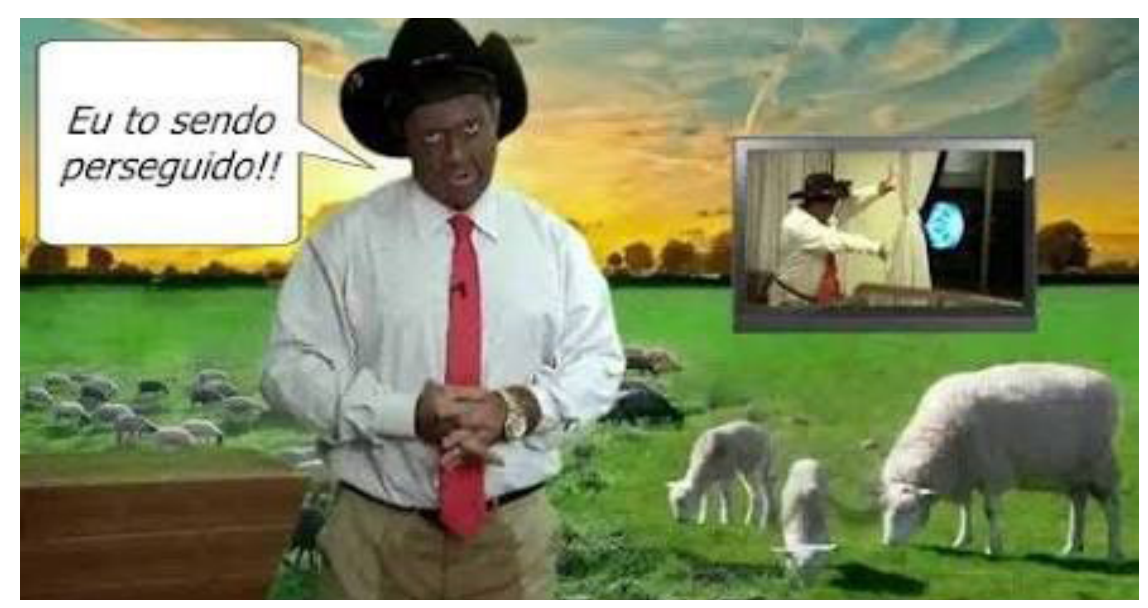

Figura 6. Valdemijo Sandiabo

Fonte: https://br.pinterest.com/pin/108860515977953486/. Acesso em: 15 maio 2019.

Com o nome do líder da IMPD, os humoristas do Pânico conseguiram criar dois cruzamentos vocabulares, ambos por entranhamento lexical, na proposta de Gonçalves (2003): os dados revelam que as bases, embora não sejam do mesmo tamanho, compartilham idêntica estrutura métrica e porções fônicas iguais ou equivalentes; fundem-se de tal modo que geram, no nível de palavra resultante, inúmeras relações de correspondência de um-para-muitos entre a forma cruzada e suas matrizes lexicais, como se vê nas representações abaixo, em que linhas sólidas indicam segmentos idênticos e linhas pontilhadas, correspondência parcial: 
(14)

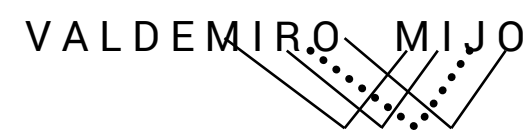

VALDE

MI RO

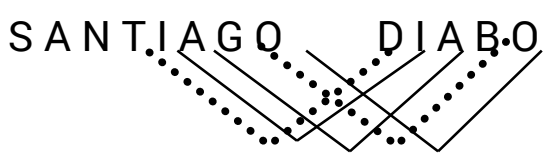

SAN
TI A G 0

Outros casos de entranhamento lexical envolvendo o prenome do ex-pastor da IURD e hoje líder da IMPD são listados a seguir e quase todos vêm acompanhados da expressão "rei do gado", que o notabilizou em decorrência da suspeita de enriquecimento ilícito através da comercialização de bovinos. Esse fato rendeu inúmeros vídeos cômicos sobre o pastor, inclusive pela Porta dos Fundos, uma produtora de vídeos de comédia veiculados na internet, sendo atualmente o sexto maior canal brasileiro no YouTube (https://www. youtube.com/watch?v=_4UEhll222s\&vl=pt. Acesso em: 02 maio 2019).

15)
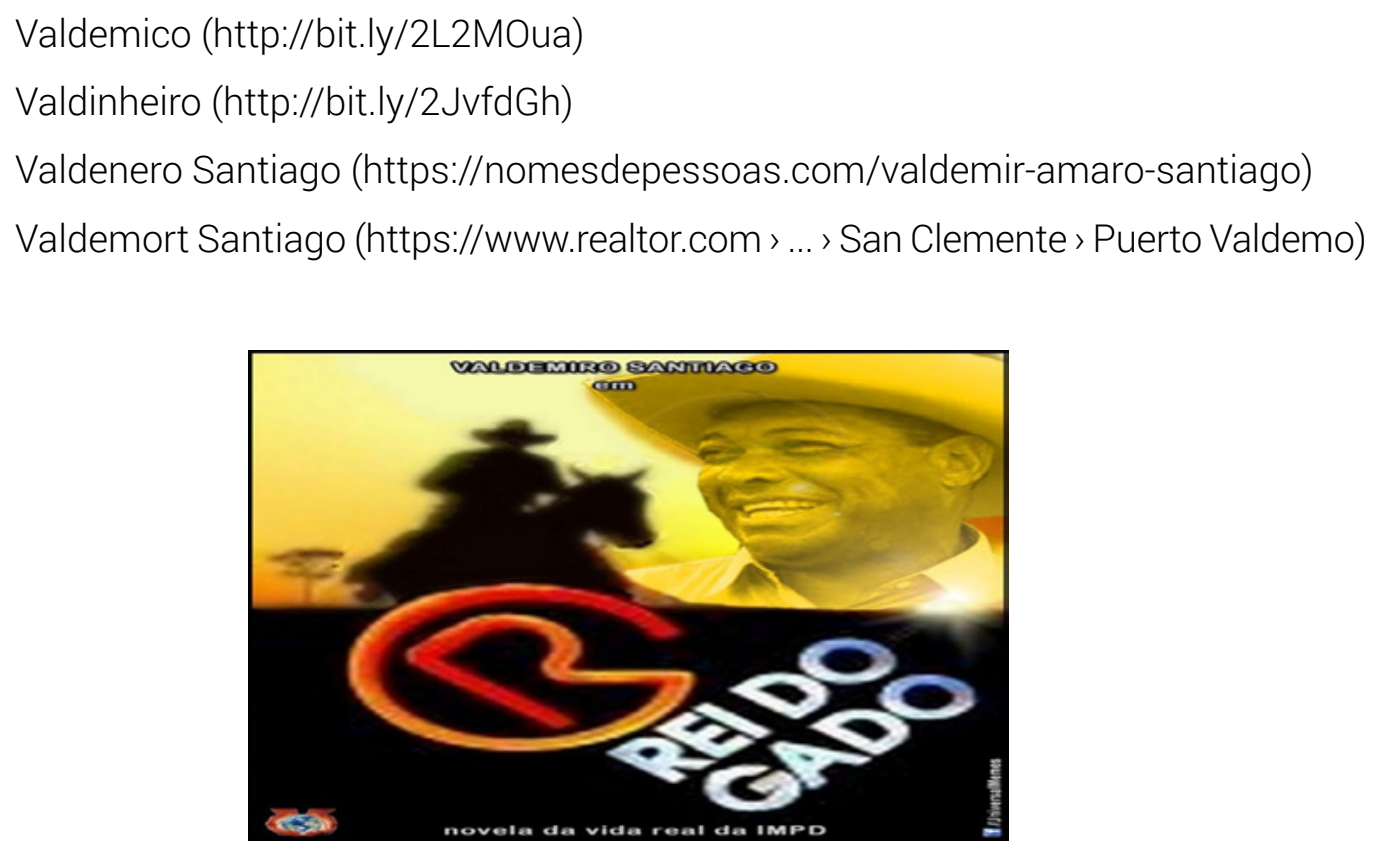

Figura 7. Valmemijo - o rei do gado

Fonte: https://desciclopedia.org/wiki/Valdemiro_Santiago. Acesso em: 15 maio 2019.

Basilio (2010) se refere a casos como os em (15) através da sigla FUVE (FUsão Vocabular Expressiva). Segundo ela, "as fuves não são formações inocentes, ao contrário, têm a função de nos levar a considerar novas (ir)realidades, seja pela contradição, seja pela maximização da força simbólica de elementos já existentes" (BASILIO, 2010, p. 05). Sem dúvida alguma, é isso que ocorre nas formações em (15), pois indicam "intenções, 
sentimentos e atitudes dos falantes" (ANDRADE, 2009, p. 196), além de gerar sensação de desvio, "causando a noção de algo inesperado e, não poucas vezes, manifesta humor, deboche, escárnio e ironia - sendo então, neste caso, eficaz para ridicularizar a imagem de determinadas pessoas, bem como provocar o riso em outras" (BENFICA da SILVA, 2019, p. 123).

Também foram encontrados no corpus dados envolvendo o candidato à presidência da república em 2018 conhecido como Cabo Daciolo. Embora bombeiro, militar e político, Daciolo primeiramente se destacou como figura excêntrica e religioso fanático. Suas opiniões polêmicas ficaram em evidência na sua expulsão do PSOL (Partido Socialismo e Liberdade), ao "defender a libertação dos doze policiais acusados de participar da tortura e morte do pedreiro Amarildo Dias de Souza em 2013" (https://www.revistaforum.com. br/cabo-daciolo-ex-grevista-bombeiro-do-psol. Acesso em 01 maio 2019). De acordo com a Wikipédia, o diretório nacional do PSOL decidiu "expulsar Daciolo do partido depois que ele propôs uma emenda constitucional para alterar o parágrafo primeiro da Constituição Brasileira de "todo poder emana do povo" para "todo poder emana de Deus"'" (https://pt.wikipedia.org/wiki/Cabo_Daciolo. Acesso em: 02 maio 2019), o que fere frontalmente a constituição brasileira, segundo a qual o país é laico.

Nas eleições presidenciais de 2018, Daciolo foi candidato pelo partido Patriota, conseguindo ser o sexto mais votado. Durante a campanha, dava declarações polêmicas e irreverentes, como a "profecia" de que seria eleito o próximo presidente: "eu estou profetizando pra nação brasileira, eu vou ser o próximo presidente da república, pela honra e glória do senhor Jesus, em primeiro turno com 51\% dos votos" (https://pt. wikipedia.org/ wiki/Cabo_Daciolo. Acesso em: 02 maio 2019). Ainda de acordo com o Wikipédia, "suas declarações fizeram com que se tornasse alvo de memes na internet e uma figura popular na época, muito pelo seu jeito evangélico e por representar uma figura estereotipada do pastor evangélico brasileiro". Um dos memes mais frequentes de Daciolo é o seguinte:

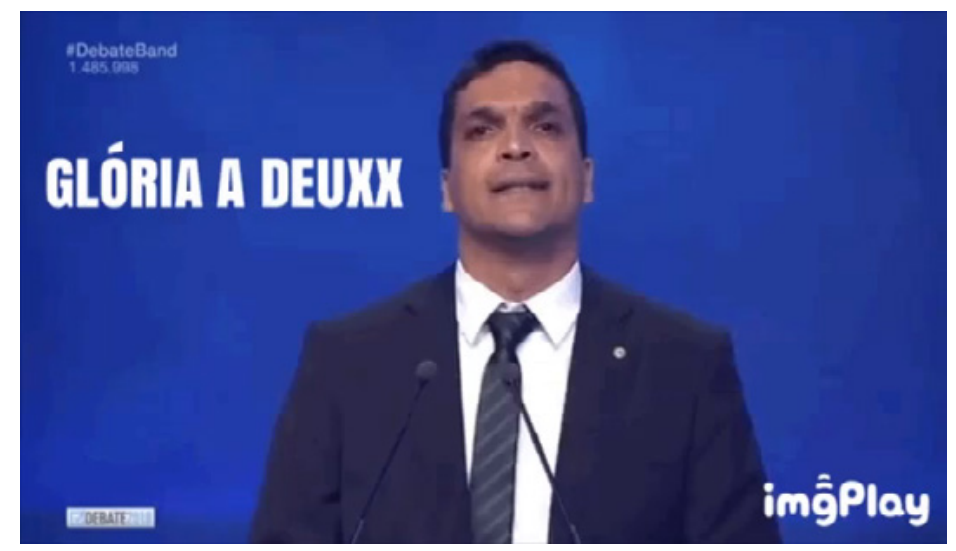

Figura 8. Cabo Daciolo - Glória a Deus em seu sotaque carioca bem marcado

Fonte: https://tenor.com/search/gloria-deus-gifs. Acesso em: 15 maio 2019. 
Os discursos do político-militar-pastor durante a campanha eleitoral soavam como uma espécie de miniculto e suas frequentes aparições "no monte" renderam a Daciolo cruzamentos como os em (16):

\author{
Cabo Dacidoido (https://twitter.com/dacidoido) \\ Cabo Dacilouco (https://twitter.com/diimabr/status/1028093717448728576) \\ Cabo Dacibobo (https://twitter.com/proftiagod)
}

Os cruzamentos envolvidos nos dados em (16) não são casos de entranhamento lexical, uma vez que não há compartilhamento de material fonológico. Na terminologia de Almeida e Gonçalves (2006) e Andrade (2009), podem ser denominados de combinação truncada, uma vez que uma parte não morfêmica da palavra é encurtada e se articula com outra (completa ou igualmente encurtada). Nesses casos, portanto, não há acesso à ambimorfemia, fenômeno cunhado por Piñeros (2002) para dar conta de casos em que segmentos do cruzamento vocabular pertencem às duas formas de base, por serem idênticos ou semelhantes. De acordo com Gonçalves (2016), o compartilhamento de unidades fonológicas (sons, sequências fônicas), decorrente da interposição de palavras matrizes, só evidencia atuação da ambimorfemia se a semelhança for condizente com posições na estrutura da sílaba: onset, núcleo, coda e rima. Os dados em (16) só apresentam em comum a vogal final átona, [๖], o que muito improvavelmente responderia pela ambimorfemia. A evocação ao sobrenome Daciolo é garantida pelo tamanho da parte suprimida, o que confere ao produto uma estrutura métrica idêntica à da base mais longa. No entanto, diferem dos referentes a "Malafaia", por exemplo, em que a sequência inicial, embora não morfêmica, é interpretada como tal, por similaridade com uma palavra da língua.

Por ser uma figura carismática e por ser um homem jovem e bonito, cruzamentos envolvendo Daciolo são os únicos do corpus que também envolvem avaliações positivas, a exemplo dos seguintes:

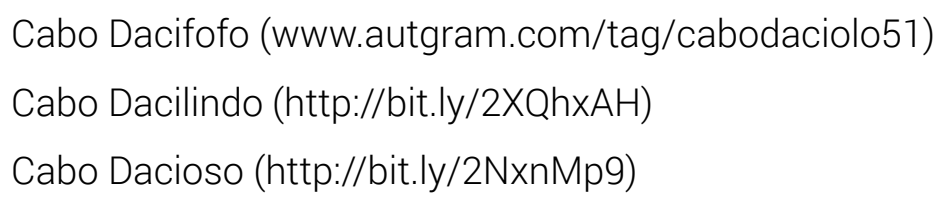

O único exemplo de entranhamento de (17) é Dacioso, pois, nesse caso, nos termos de Basilio (2005, p. 3), do lado fonológico, "temos a superposição de um outro significante sobre o significante da palavra base hospedeira", mas de tal maneira que se atinge, com 'cioso' (que tem muito apreço, zeloso), "não apenas uma superposição, mas um entranhamento ou incorporação". Do lado do significado, "temos uma forte evocação do significado da palavra incorporada, como predicação que passa a integrar o sentido da palavra base" (BASILIO, 2005, p. 3). A representação é vista em (18), a seguir: 
(18)

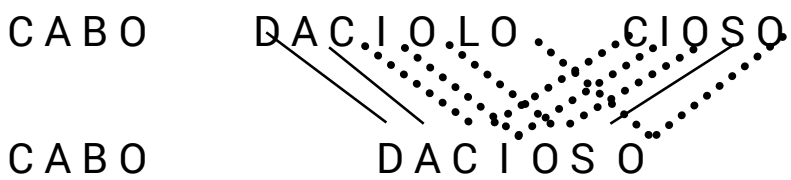

O último líder neopentecostal de cujas (des)construções lexicais iremos tratar é "Marcelo Crivella". O também bispo da Universal já era conhecido por sua ativa participação na IURD, mas se tornou figura pública quando ingressou na carreira política. Foi eleito senador em 2002 e em 2010. Foi concorrente direto de Luiz Fernando Pezão nas eleições para o Governo do estado do Rio de Janeiro e, logo depois, vencedor das eleições para o município do RJ, sendo o prefeito da cidade até o momento.

Como prefeito, Crivella é constantemente acusado de sobrepor questões religiosas a problemas de ordem política, o que lhe rendeu o epíteto de "bisprefeito", cruzamento vocabular por entranhamento lexical de "bispo" com "prefeito". De acordo com o Wikipédia, essa mistura entre religião e política levou Crivella a pronunciar, durante um culto, a seguinte profecia: "Os Evangélicos ainda vão eleger um presidente da república que vai trabalhar por nossas igrejas para cumprirmos a missão de levar o evangelho a todas as nações da Terra" (https://pt.wikipedia.org/wiki/Marcelo_Crivella. Acesso em: 02 maio 2019).

Sua atuação na Prefeitura do Rio de Janeiro não vem sendo bem avaliada pelos cariocas, que o consideram um dos piores prefeitos que a cidade já teve (https://www.anf.org. br/o-pior-prefeito-da-historia-do-rio-de-janeiro/. Acesso em: 01 maio 2019). Envolvido em polêmicas ou mesmo em crimes de improbidade administrativa, o sobrenome do prefeito aparece em decomposições lexicais como as seguintes:

$$
\begin{aligned}
& \text { Marcelo Que Merda (http://bit.ly/2LFbg4n) } \\
& \text { Marcelo Que Mela (http://bit.ly/2Xq4cuv) } \\
& \text { Bispo Que Não Vela (https://pt-br.facebook.com/permalink.php?story) }
\end{aligned}
$$

Seu desempenho, avaliado de forma negativa por grande parte das pessoas, deu origem a diversas substituições lexicais que, em comum, rimam com o sobrenome do prefeito, de modo pejorativo, cômico ou debochado:

(20) Marcelo Balela (http://bit.ly/2XVU55j)

Marcelo Fivela (https://profcarlosazevedo.wordpress.com/2017/06/)

Marcelo Canela (http://bit.ly/2L3RVdM) 
Um episódio no qual o bispo ofereceu atendimento prioritário aos membros de sua igreja por meio de sua secretaria, Márcia, criou muita discussão nas mídias impressas, repercutindo, consequentemente, nas mídias sociais: o CV CriMárcia, caso claro de combinação truncada, em que a sílaba inicial do sobrenome do prefeito se adjunge ao prenome de sua secretária, constitui reminiscência dessa crítica. De acordo com a Wikipédia (https://pt.wikipedia.org/wiki/Marcelo_Crivella. Acesso em: 02 maio 2019),

Alguns vereadores tomaram a iniciativa de pedir uma abertura de processo de impeachment de Crivella como prefeito do Rio por improbidade administrativa, em julho de 2018, em decorrência de uma "reunião secreta" com um grupo de pastores, no Palácio da Cidade, no qual indicou facilitações de acesso a auxílios, como cirurgias de catarata e varizes, do governo municipal a estes grupos evangélicos.

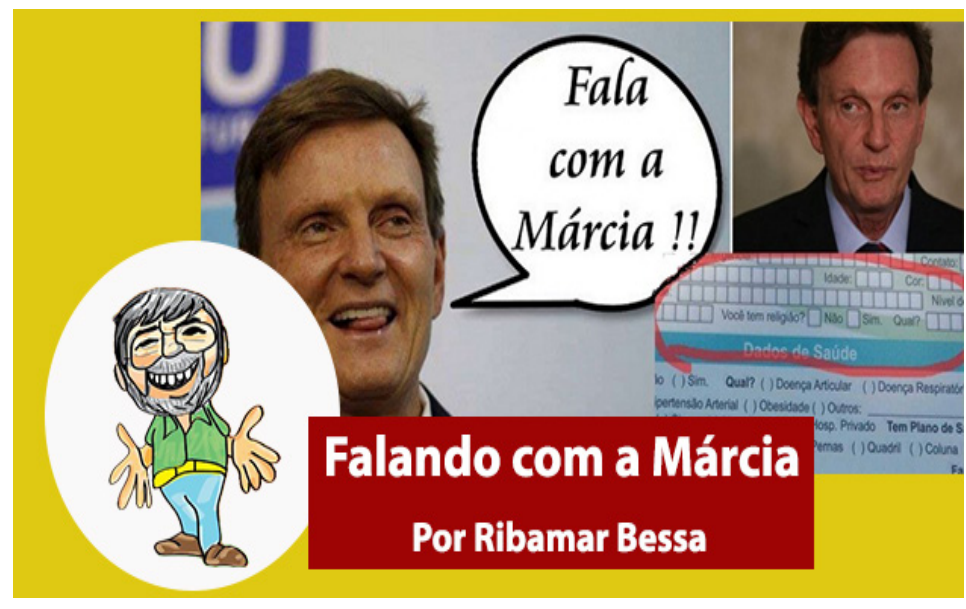

Figura 9. Marcelo Crivela e assessora Márcia

Fonte: https://www.blogdosarafa.com.br/?p=32185. Acesso em: 15 maio 2019.

\section{Palavras finais}

Neste trabalho, utilizamos um conjunto de novas (des)construções lexicais que, em comum, partem de nomes de personalidades polêmicas na liderança de igrejas evangélicas. Observamos que vários processos morfofonológicos ocorrem no intuito de depreciar a imagem desses líderes neopentecostais, o que revela, através da língua, avaliação negativa dos falantes/escreventes, sobretudo os contrários às ideias pregadas pelas igrejas que fundaram e/ou dirigem. Embora estejam relacionados ao uso criativo da linguagem e sejam efêmeros e fortemente dependentes de contexto para serem interpretados, tais usos revelam habilidades cognitivas como a analogia, ajudando-nos a compreender como o falante (des)constrói construções por similaridades e expõe 
ponto de vista, ora desfazendo uma palavra simples (decomposição sublexical), ora trocando uma palavra de um nome composto (substituição lexical), ora fundindo duas outras (cruzamento lexical - CV). Também são variados os tipos de CV envolvidos, o que corrobora a tipologia de Gonçalves (2003), Basilio (2005) e Andrade (2009) também em cruzamentos com nomes próprios e compostos: (a) entranhamento lexical (com acesso à ambimorfemia), (b) combinação truncada (com uma ou as duas bases encurtadas) e (c) substituição sublexical (com reanálise de uma parte da palavra como morfêmica e substituição das demais partes por uma palavra invasora). Essas formações comprovam que a linguagem é sócio-culturalmente situada, pois, vingando ou não, pelo menos deixam, na língua, sobretudo nessa era digital, vestígios de como o falante avalia determinadas entidades em um período sócio-histórico específico.

\section{REFERÊNCIAS}

ALMEIDA, M. L. L.; GONÇALVES, C. A. Bases semântico-cognitivas para a diferenciação de cruzamentos vocabulares em português. Revista Portuguesa de Humanidades, Braga: Faculdade de Filosofia da UCP, p. 45-59, 2007.

ANDRADE, K. E. Entranhamento lexical, combinação truncada e analogia: Estudo timalista sobre padrões de Cruzamento Vocabular. In: GONÇALVES, C. A. (org.). Otimalidade em foco: morfologia e fonologia do português. Rio de Janeiro: Publit Soluções editoriais, 2009. p. 123-145.

ANDRADE, K. E.; RONDININI, R. As "ianes" do porão: análise morfo-pragmática das atuais construções X-iane. SCRIPTA, Belo Horizonte, v. 20, n. 38, p. 121-147, 2016.

BASILIO, M. M. P. Fusão vocabular expressiva: um estudo da produtividade e da criatividade em construções lexicais. In: XXV Encontro Nacional da Associação Portuguesa de Linguística, Porto: APL, p. 201-210, 2010.

BASILIO, M. M. P. A fusão vocabular como processo de formação de palavras. In: Anais do IV Congresso Internacional da ABRALIN. Salvador: UFBA, 2005. p. 1-15.

BASILIO, M. M. P. Teoria Lexical. São Paulo: Ática, 1987.

BENFICA da SILVA, V. O cruzamento vocabularformado porantropônimos: análise morfológica e fonológica. 2019. Dissertação (Mestrado em Letras Vernáculas) - Faculdade de Letras, Universidade Federal do Rio de Janeiro, Rio de Janeiro, 2019.

BECKMANN, J. N. Positional Faithfulness. Massachussets: Amherst, 1998. 
HENRIQUES, C. C. Morfologia: estudos lexicais em perspectiva sincrônica. Rio de Janeiro: Elsevier, 2007.

GONÇALVES, C. A. Atuais tendências em formações de palavras. São Paulo: Contexto, 2016.

GONÇALVES,C.A. Blendslexicaisem português:não-concatenatividadeecorrespondência. Veredas (UFJF), Juiz de Fora, v. 7, n. 1-2, p. 149-167, 2003.

GONÇALVES, C. A.; ANDRADE, K. E.; ALMEIDA, M. L. L. Se a macumba é para o bem, então é boacumba: análise morfoprosódica e semântico-cognitiva da substituição sublexical em português. Linguística, Rio de Janeiro, v. 6, p. 64-82, 2010.

GONÇALVES, C. A. V. A. et al. Para uma estrutura radial das construções X-ão do português do Brasil. In: ALMEIDA, M. L. et alli. (org.). Linguística Cognitiva em foco: morfologia e semântica. Rio de Janeiro: Publit, 2010. p. 141-156.

PIÑEROS, C. E. The creation of port manteaus in the extragrammatical morphology of spanish. Iowa: University of lowa, 2002.

SANDMANN, A. J. Morfologia lexical. São Paulo: Contexto, 1989.

SOUZA, E. F. R.;GONÇALVES, C. A. V. Linguística Textual e Morfologia. In: FRANCISCO DE SOUZA, E.; PENHAVEL, E.; CINTRA, M. R. (org.). Linguística textual -Interfaces e delimitações - Homenagem a Ingedore Grünfeld Villaça Koch. v. 1. São Paulo: Cortez, 2018. p. 144-188. 